\title{
Design possibilities for the e-Schoolbag: Addressing the 1:1 challenge within China
}

\section{Xiaoqing Gu, Xiaojuan Xu, Huawen Wang and Charles Crook}

Xiaoqing Gu is a professor of educational Technology, her research interests include including learning design, ICTintegrated pedagogical innovation, computer-supported collaborative learning. Xiaojuan Xu and Huawen Wang are research assistants working with Professor Gu. Charles Crook is a professor and director of Learning Sciences Research Institute (LSRI), his research interests include: how can insights from the psychology of child development be applied to the design of learning technologies, how can these designs then be best integrated with existing cultures of teaching and learning. Address for correspondence: Xiaoqing Gu, 3663 Zhangshan Road North, Shanghai, China. Email:xqgu@ses.ecnu.edu.cn, guxqecnu@gmail.com

\begin{abstract}
There is widespread enthusiasm for 1:1 computing in education. Recognizing that secure innovation of educational practice should be built upon contextual sensitivity, this article reported two case studies anticipating the potential development of 1:1 classes in the particular cultural context of China. The first case described how the new technology of e-Textbooks could align with a tradition where the textbook is central to teaching practice. A science teacher used the e-Textbook to design his pedagogy to accommodate the contextual learning needs of the classroom. Students reported a positive reaction. They understood that new learning possibilities were crafted through this engagement with diversified media formats that content fitted their class, and this gave them increased confidence in relation to both student-computer and interpersonal interaction. The second case study described how a social app could align with the local tradition of practice whereby a student's performance in front of class is an important part of instructional practice. In this case, students who were learning native Chinese were offered the opportunity for performing within a novel "digital stage": revealing high levels of engagement and a strengthening confidence with language performance.
\end{abstract}

\section{Introduction}

Within debates upon the state of contemporary education there are some voices that are enthusiasitc about digital technology as key to making necessary progress (eg, Collins \& Halverson, 2009), while other voices are more sceptical (eg, Cuban \& Cuban, 2009). Certainly, the promise of transformation through technology has frequently been made and it is increasingly raising interest in China. There are many ways to map the trajectory of digital influence on educational practice: commentators often identifying distinct periods of a dominant fashion or enthusiasm, such as the successive "eras" of broadcasting, constructionism, multimedia, collaboration, and participation (Crook \& Lewthwaite, 2010). Evidently these themes overlap but, as implied in the trajectory labeling, there are apparent discontinuities and with each an expectation of fresh transformative possibilities. Such claims are currently being made for the potential impact of new technology designs that: (1) encourage the possibility of widespread personal ownership of a powerful digital device and (2) enable that device to be readily portable. So our own interest is in exploring the promise of this new "era" of digitally mediated learning. In particular, we are 


\section{Practitioner Notes}

What is already known about this topic

- It is recognized that 1:1 computing has the potential to empower students learning whereas innovative designs are needed.

- Secure innovation of educational practice should be built upon contextual sensitivity

- The well-established classroom practice in China features as (1) the textbook has a key role, and (2) students enjoying participatory performance in classroom.

What this article adds

- Illustrate a strategy for innovation that involves taking a novel opportunity and carefully interfacing it with well-established classroom practice.

- Describes a case that aims to use a pedagogically sound methodology in designing the e-Textbook to accommodate the contextual learning needs of the classroom.

- Describes a case that was to offer students an opportunity for working within a more community structure.

concerned to understand how the developments it affords harmonise with robust and wellestablished traditions of educational practice already established in the contexts of innovation.

The popularity of personal mobile devices has fuelled interest in recruiting this technology to transform the classroom. For example, "One Laptop per Child" (OLPC) is a large-scale project to improve learning in developing countries by providing low-cost laptops for school and home (Nugroho \& Lonsdale, 2010). While in "Bring Your Own Device" (BYOD), students bring personal mobile devices to school for learning (Norris \& Soloway, 2011). More generally, "1:1 computing" refers to projects where technology is available to all students and their teachers (Bebell \& O’Dwyer, 2010). Such developments are now arousing interest in China, where the personal digital device in class has been termed the "e-Schoolbag" initiative. The present article considers how easily such initiatives can align with the firmly established traditions of Chinese basic education.

One finding echoed in recent 1:1 projects across the world is that when these technologies are implemented, the effect is much less transformative than expected (Balanskat et al, 2013; Bebell \& Dwyer, 2010; Lindqvist, 2015; Nugroho \& Lonsdale, 2010; Tierney, 2012). Further research may be required to indicate how best to innovate 1:1 classroom practice. Understanding the dynamic of change in the particular cultural circumstances of the Chinese classroom may be one important aim in this context. Such cases may indicate what design possibilities arise in a culture of classroom practice that is strongly teacher-led. The rapid adoption of personal digital devices in the Chinese education system has attracted the metaphor of "e-Schoolbag," perhaps because it indicates the central role of the schoolbag and its textbook in traditional classroom practice (Li, Chen, \& Kulm, 2009; Ma, Zhao, \& Tuo, 2004).

The 1:1 classroom vision has spread fast in China: entailing widespread adoption of mobile devices, along with development of the e-Textbook (Embong, Noor, Hashim, Ali, \& Shaari, 2012; Gu, Fu, \& Qi, 2013). Shanghai, eg, is leading an initiative to transform sites across the city into ICT-rich learning environments (Goodyear \& Retalis, 2010; Gu et al, 2013): places where a personal "eSchoolbag” becomes a powerful resource for learners (Jiang, Zheng \& He, 2013; Lai \& Lai, 2013). In a tradition of instruction that relies heavily on the textbook, the emerging e-Textbooks may become 
implicated in how teachers could innovate practice within the 1:1 class. Innovative instruction is desperately sought within Chinese education, where practice has been more teacher-centered (Paine, 1990), such that students' minds-on and hands-on activities are too often limited (Tan, 2014).

To anticipate the potential development of 1:1 classes in the particular cultural context of China, two case studies are reported here involving native Chinese-speaking students in elementary schools. They each illustrate a strategy for innovation that involves taking a novel opportunity and carefully interfacing it with well-established classroom practice. Our approach supposes that if the practitioner understands real continuity between existing practice and the innovation, then adoption is more likely. Moreover, if an exploratory innovation can function as the first step on a longer trajectory of educational development, then such an intervention offers the prospect of genuine transformation. In the present context, this might comprise a positive and inquiring orientation to opportunities associated with the e-Schoolbag.

The first case aims to use a pedagogically sound methodology in shaping the e-Textbook to accommodate the contextual learning needs of the classroom. We have already stressed the central place of the textbook in China. It is the key in the management of the curriculum and the organization of classroom discourse. Commentators note the discrepancy between the United States (eg) and China in relation to teachers' agency in respect of textbook content (Li, 2008). In the first of our interventions, therefore, we invited a classroom teacher to take up the role of designer in shaping the content of the class text. Both the design and the access to its outcome by students were made possible by the tablet technology at the heart of the eSchoolbag idea. Other authors (Friesen, 2013) have celebrated the potential of the textbook to personalize instructional engagements with the student. Friesen highlights how this might be achieved through designing implicit forms of conversation with the reader. However, another approach to personalization is to displace authorship responsibility to the students' teacher, thereby enriching cross referencing between text and other conversations and classroom activities, as well as making illustrations more local in flavor. This has been the approach taken here. Although there has been interest in designs that are tailored to particular classrooms (eg, Sun, Tian, \& Shen, 2013), there is little research that evaluates the impact of a class teachers' own design status in this medium. Moreover, striving for such status is of particular interest in China where both teacher and text have highly valued but, nevertheless, distinctive roles within educational practice. Exploring the tensions and harmonies that might exist between them seems timely.

The second case describes an intervention based on cultivating the students' sense of community in their classroom. The intended continuity of practice fostered in this case is not the text, but the Chinese students' engagement with the classroom contributions of their peers. For example, in their ethnographic work in Chinese schools, Jin and Cortazzi (1998) comment on the practice of students publically answering questions as they are directed in sequence to volunteer (or designated) respondents with invitations to stand and speak. The researchers note: "Most pupils therefore already know what will be said but they still give avid listening attention. It is possible, as Coleman (1996) shows in the very different Indonesian large class context, that learners simply enjoy a performance" (p. 744). Therefore, our approach in this second case study was to use the resources of the e-Schoolbag to produce a variant of such "presence-through-voice": namely, sound-photographs to which a student narration has been added. These artifacts would be made by students and shared with peers around classroom discourse. We supposed that this would create a useful continuity with the "performance" tradition cited above.

The cases reported here could contribute to understanding how a more convivial and seamless transition to new methods can be achieved: one that promises the opening of a new trajectory for transformations. 


\section{Case 1: The teacher's voice in the e-schoolbag}

This case aims to accommodate an e-Textbook to the contextual learning needs of a Chinese classroom, by aligning this innovation with the strong tradition of the textbook mediating classroom discourse. One of the most significant features of a Chinese textbook is a pedagogical sequence defining the main thread of content. Yet teachers will often feel they need to transform this into their own pedagogical design. An e-Textbook affords a flexibility toward doing this.

\section{Research questions}

The present purpose is to determine how teachers can exploit e-Textbook features to support adaptively designing and redesigning their teaching. This suggests the following research questions:

1. Can a pedagogically driven design methodology provide effective and contextualized learning opportunities?

2. To what extent can students and teachers adapt to a redesigned pedagogy that is adapted to the tradition of the textbook?

\section{Redesign of the e-Textbook}

The e-Textbook was a science unit, "Endangered and Extinct Wildlife." The instructor was invited to take the role of designer in transforming the e-Textbook content to best fit the context of his class. Four sessions were included in this unit: "Get to know dinosaurs," "The extinction of dinosaurs," "Fossils," and "The conservation of wildlife." He took the main role in determining the design of the unit but took part in discussions with the researchers in order to negotiate the precise design of the software product. To this end, an editing tool was provided along with a number of re-usable learning objects that could be selected, annotated, and sequenced.

This digital version of the print text featured: (1) thicker background information, (2) formats of learning content ranging from text to videos, and (3) links to outside resources. For example, the first session of "Get to know dinosaurs" provided students with two pages of after-school learning materials, including links to Fossil Web (http://www.uua.cn) and a museum website (http:// www.paleozoo.cn/). Additionally, students could get adapted feedback to their inputs, could make personalized annotations, or write down their personalized understanding of the problems, and then share with their peers.

With the e-Textbook, an editing tool was provided, along with re-usable learning objects. It allowed the designer to control topic sequences and to install learning objects on a page, including the copying, pasting, deleting, and adding of new items. For example, the learning object of the dinosaur was amplified for this class by inserting strategically selected pictures from the above websites, and by offering links to the websites as well. The designer could also adjust the sequence of pages by dragging them into targeted positions.

Data collection, the instruments, and the process

The intervention involved an elementary school in east China. All 40 students of Grade 4 (9 or 10 years old) were taught over a period of 6 weeks by a science teacher with extensive experience. The students had already used iPads in classes for 1 year, thus they had good ICT competence. In this case, the iPads were used by the students in class as the source of reading, video watching, and doing skill exercises. They were not used for homework.

The intervention comprised four dedicated 45-minute sessions following a redesign by the instructor. A 1-hour interview was conducted with the instructor at the end of the third session and concerned the following issues: (1) technical background of the teacher, (2) evaluation of the design and usage of the e-Textbook compared with a conventional textbook, including 
advantages, underlying problems, and its function for participant interactions, and (3) evaluation of the affordances of a flexible pedagogical design of the e-Textbook. Students completed a questionnaire at the end of the project, and interviews with the students were then conducted on a voluntary basis, covering the following issues:

- Overall satisfaction of the e-Textbook.

- Rich provision of media and links.

- Opportunities provided for in-class activities.

- Opportunities provided for afterschool activities.

Student feedback was collected through questionnaires and interviews. The questionnaire, with 18 multiple choice questions employed 5-point Likert-type scales from 1 (not satisfied/sufficient/ precise) to 5 (very satisfied/sufficient/precise), and an open question asking "what else do you expect from an e-Textbook?". The questionnaire measured six components relating to students' perceptions of the e-Textbook: content, format, interaction, ease of use, motivation, and overall evaluation. The items of "content" and "ease of use" were developed by adapting the End-User Computing Satisfaction Instrument reported by Doll and Torkzadeh (1988). About 39 out of the 40 participants provided valid data.

Interview questions were phrased in the manner of a conversation. Typical questions were: "overall, how do you like the e-Textbook?"; "what part of the designs do you like the most and why?," "Comparing the e-Textbook and your familiar textbook, which do you think is more helpful for you to interact with the teacher and your classmates?," plus the same open question as is used in the questionnaire. About 14 students were interviewed. The recorded interviews were processed by two interviewers. All these were done in Chinese except the preparation of this report.

\section{Results and discussion for case 1}

Using data from survey and interview, we present the students' reaction to the e-Textbook in general, but identifying some particular features that were effective: their general reaction, their reaction to specific resources, and their impression of its support for interaction. Then we report the teacher's perception of its pedagogic flexibility.

Students' perception of e-Textbook and its learning opportunities

Both survey results and interview indicate that the e-Textbook was considered positive in all six aspects: content, format, interaction, ease of use, motivation, and overall evaluation. From using the flexible pedagogically designed e-Textbook, students showed positive learning attitudes, learning motivation, and reported high ease of use: all of which indicated that this flexible methodology did help to provide contextualized learning opportunities for students.

About 95\% of students reported "very" or "quite" satisfied responses to the e-Textbook. This overall satisfaction was further verified in student interviews. For instance, several students mentioned that they wanted to learn more units or even all elementary knowledge in the e-Textbook. Although such interventions always carry the risk of Hawthorne Effects, we remain impressed with the confidence and consideration with which these reactions were expressed.

A large majority (95\%) "very much" or "quite" agreed that they preferred to take classes with e-Textbook, 95.0\% of students were surprised by the content provided and $90.0 \%$ felt "very" or "quite" proud of taking classes with an e-Textbook. On preferences to study privately with an e-Textbook, $87.5 \%$ said they would very much "love to" and $5.0 \%$ were "quite willing to." The percentages of students reporting the e-Textbook as easy to use, easy to learn how to use, and user-friendly were $90.0 \%, 97.5 \%$, and $90.0 \%$ respectively. Similarly, interview findings indicated that perception of the e-Textbook was favorable. For instance, two students mentioned that with 
the multimedia content provided they enjoyed the learning and were willing to prepare the lesson before the class which, in turn, made them interact more confidently with the teacher during class. In short, the design of e-Textbook content stimulated students' learning and motivation, and enhanced interaction between teacher and students.

Secondly, the opportunities provided by the e-Textbook revealed the extent to which redesigned pedagogy can go beyond the resource limitations of the classroom. For instance, the teacher observed in the interview that limitations of the printed Natural Science textbook would require the teacher to spend time searching for appropriate materials to further extend students' knowledge. But taking advantage of the rich content, the reusable learning objects, and the easyoperate nature of the editing tool, meant that the teacher could avoid this effort; while students could overcome the limitations of conventional course content and research beyond the classroom. Students were enabled to find learning resources matching their own learning needs.

The diverse media formats for the learning materials turned out to be the most important feature that attracted the students. About $90.0 \%$ of students reported that e-Textbook provided sufficient formats to display content effectively. Similarly, 82.5\% "very much" agreed and $7.5 \%$ "quite" agreed that the e-Textbook was better able to attract students to learn by providing varied formats of learning content. About $97.5 \%$ students were "satisfied" (87.2\% very and $10.3 \%$ "quite satisfied") with those formats. Findings from the interviews echoed this. In several of the interview questions one of the most frequently mentioned features attractive to students was the varied media formats. Cited comments included: "the most favorable design attracting me to learn is it using animations to teach, which are clear and easy to understand," "There is introduction in videos, and that's where e-Textbook helps me most," and "The images and videos are very clear, that's where I feel satisfied and it attracts me to learn."

The unlimited boundary of the learning materials was a further salient feature. With links to related knowledge bases, the content that the students could reach felt sufficient to meet their learning needs $(97.5 \%)$. Yet in the open questions and interviews students also expressed an appetite for more flexibly linked content. They mentioned that they could learn by themselves out of the class, something which was made possible by the e-Textbook and, moreover, they desired to do so: "the extra knowledge is very rich and unknown to us, so we feel very curious to explore."

Enhanced interaction provided by the e-Textbook was another way this redesigned pedagogy extended the classroom experience. Both student-computer interactions and interpersonal interactions triggered by e-Textbooks were enhanced. In terms of student-computer interaction, the majority of students agreed that the interactions with the e-Textbook could meet their demands $(95.0 \%)$, they felt satisfied with the interaction $(94.9 \%)$ which was attractive to them $(90.0 \%)$. The interaction between students and the e-Textbooks was closely linked to media formats, such as playing video or rotating a three-dimensional (3D) learning object. This was mentioned by many students as the most satisfying design of e-Textbook. Also, ways of interacting with learning content by dragging, moving, and playing were fascinating to students: "Usually you just sit there listening to the teacher, but with e-Textbook you can make something and do some reading."

The interpersonal interactions triggered by the e-Textbook were even more positive from the interviews. When asked if the e-Textbook would fix them too firmly to their screens at the expense of interactions with the teacher or peers, the interviewed students said not, often elaborating just how the e-Textbook changed their interaction. For example: "I interacted more with the teacher. I raised my hand more frequently now than before." Her reason was that the e- 
Textbook gave her much richer information enabling her to elaborate explanations for interacting with the teacher.

Teacher's reflections on flexible pedagogical design

The teacher interview was conducted mainly regarding two issues: (1) evaluation of the design and usage of an e-Textbook compared with a conventional textbook, including advantages, underlying problems, effect of interaction, different effects of using e-Textbook in different grades and subjects; (2) evaluation of the affordance of a teacher-managed flexible pedagogical design.

Designing a lesson plan was part of daily work, usually based on the textbook, while adding extra resource, and adjusting the sequence were always needed to fit his class. So the teacher commented that, compared with the printed textbook, with its fixed content and sequence, the eTextbook greatly eased the process of lesson design. Design for the lesson was a "must-be" for every teacher, so the thicker information provided and the links outside resources, helping him to manipulate and personalize the content, and sequence of the lesson. The predefined pedagogical models and predefined learning objects within the e-Textbook were seen as important by the teacher. He commented that "pedagogical models are of great value, especially for novice teachers who lack teaching experience.” Moreover, the need for a variety of pedagogical models was noted. This need is still being worked on.

\section{Case 2: Finding the students voice in the e-Schoolbag}

The second case study involved a language unit for first year elementary school students studying their native Chinese language (structures, traditions, and communication practices). A social app elaborated traditional classroom exchange: aiming to create a useful continuity with the "performance" tradition of Chinese classroom practice.

\section{Research questions}

This study would investigate how personally owned devices could reproduce something of the traditional classroom participation and performance expectation. We were also concerned to support students' curriculum learning through collaboratively creating and sharing learning content. Finally, we would determine if the activity cultivated confidence in students' spoken language. The research questions were:

1. To what extent does the social app afford and extend participatory performance in the classroom?

2. How is this kind of extended class performance manifested in the students' language confidence?

Research design, participants, and process

The social app, Papa, was employed to create a novel pedagogical design and support language learning. Papa would allow photographs to "talk." Whenever a user posts a photo, Papa reminds the user to record commentary in voice, describing the story behind the photo or its content. Thereafter, this photo-message would be posted to others in the community. Although this format has been described elsewhere (Frohlich \& Jones, 2008), it has no tradition of use within educational contexts. As with other social apps, users in the Papa community can communicate with each other by following, sharing, commenting, liking, and/or adding to "favorites." This combination of communicative potential with digital imagination made the tool especially attractive.

This study was conducted in a compulsory class in which the literature, structure, and context of the students' native Chinese language was explored for the fall semester of 2013. Participants comprised one teacher and 43 first grade students, 6-7 years old. They were volunteer 


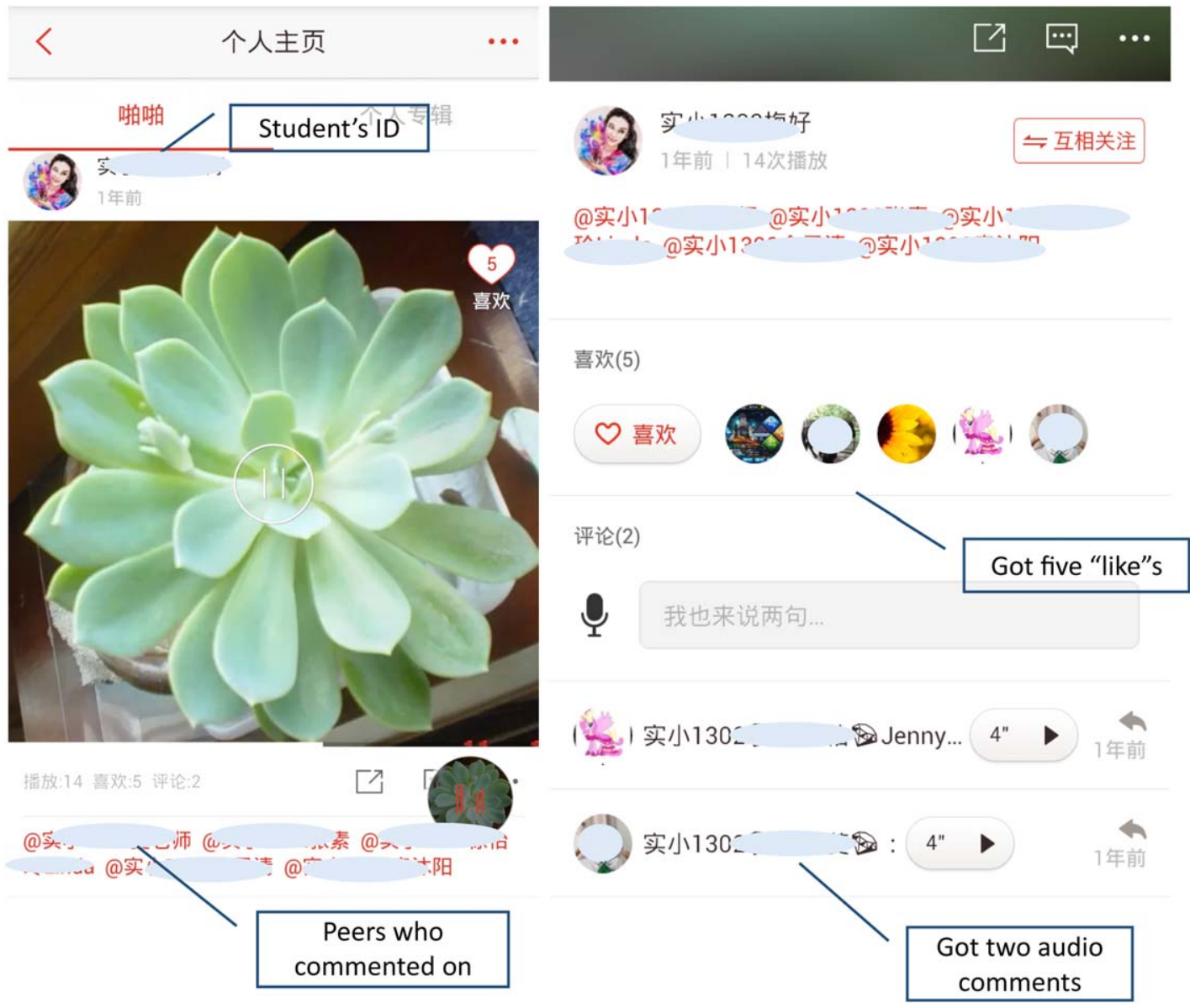

Figure 1: Snapshot of reading assignment (left) and comments from teachers and peers (right)

participants from an experimental class into which they were enrolled. All participating children had the basic skills necessary to operate iPads.

Two types of assignment were designed by the participating instructor for students: (1) every day after school, students were asked to take photos of interesting things from their personal contexts, to upload them onto Papa, and to construct spoken sentences with expressions and idioms learnt in their Chinese class; (2) once every couple of days, students were assigned reading materials in the form of a photo and were required to practice sentence-making through describing the photo; (3) both teacher and students were invited to communicate with each other by commenting, sharing, liking, and/or adding others' posts to their "favorites." Figure 1 shows a snapshot of the reading assignment of a student with five "likes" and two audio comments. The constructed sound photos effectively extended the tradition of class performance as they were publically discussed in class.

Data collection and the instruments

Both qualitative and quantitative data were collected. At the end of the semester, all content created on Papa was transcribed. This involved collecting posts, comments, lengths of each post, number of accesses and "likes" for each post, and the number of "@” ascriptions (an uploaded post copied to someone in the community who was thereby invited to interact). Quantitative data 
in the form of the number of posts per month and the length of each post was also collected. The levels of interaction of student-teacher and student-student were calculated as the proportion of “@” ascriptions for the teacher against the total posts, and the proportion of “@” ascriptions for peers against the total posts, respectively.

Qualitative analysis of posts considered to what extent the social app might support students' language learning. A five-Point Likert language competence scale was adapted from Yao \& Shi (2013) and used to analyze each post: for each of the tasks of: (1) practice reading the provided materials and (2) describing own photos. Three dimensions were used to evaluate students' language competence: content, language skill, and the emotional attitude of expression (see Appendix). Also, all these were done in Chinese except the preparation of this report.

Two research assistants, using the language competence scale, analyzed the transcribed data following 2 hours' training with the language competence scale.

Results and discussion for case 2

The findings demonstrated the potential of the app as a pedagogical tool for creative communication and one that could promote spoken language use among less confident students.

Supporting and extending participatory performance in the classroom

All participants "followed" all others in the class, including the teacher. The student-studentteacher communications took place in Papa through posts. In relation to "practicing reading the provided materials," a student usually posted their records of reading the material and a picture of the material. For "describe your own photos," students could post any photos they recently had taken when they wanted to share various scenes or interesting stories. There were 379 records posted with an average of 9 posts for each one, which acted as a vehicle for language performances and interactions. Other students in the Papa community then listened to the records, they might either click "like" or comment on it. The teacher would listen to all the posts and, if necessary, she would give words of encouragement as well as language correction of students' posts. The teacher and others students could comment or discuss asynchronously.

Compared with the traditional classroom, opportunities for students' language performance were extended, while the interactions resourced rich classroom performance. Indicators of success were the numbers of records posted by each student, the frequencies of accessing each post, and the "likes" and comments that each post attracted. On average, 9 records were posted for each student, each record had attracted at least 8 occasions of listening, while the maximum number of accesses was 41; a total of 381 "likes" for 43 students were recorded, representing 1 "like" against each post on average, where everyone attracted at least 1 "like." Regarding comments on postings: although the number was not high (99 in total), this still represented active engagement from students, considering that $82.8 \%$ of all comments were from peers. The results also showed some students as much more active than others.

In addition to vigorous student-student interaction, Papa achieved a higher level of visible student-to-teacher interaction. This satisfied the students' need for getting attention when they were academically "performing": illustrated by the fact that the teacher had played all of the students' posts, having clicked "like" to every post, and gave her comments for at least some of the posts $(17.2 \%$ of all the comments were given by the teacher).

Extending students' language confidence

The findings are presented around two dimensions expressed by the language competence scale. These are (1) practice reading the provided materials and (2) describe your own photos.

1. "Practice reading the provided materials"

Average monthly scores in respect of content, language skill and emotional attitude (as shown in Figure 2) were calculated. Students show a slow but steady improvement 


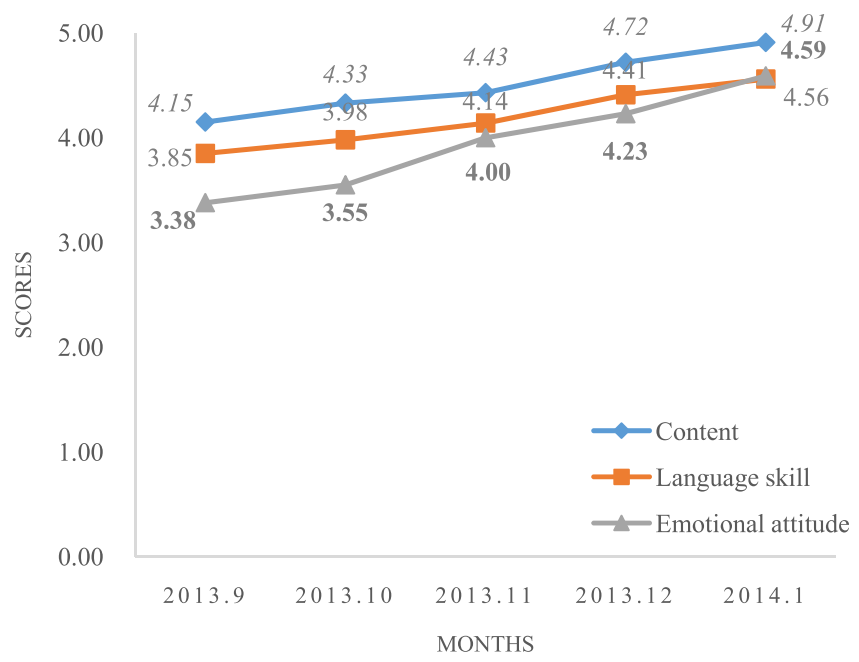

Figure 2: Scores of "practice reading the provided materials"

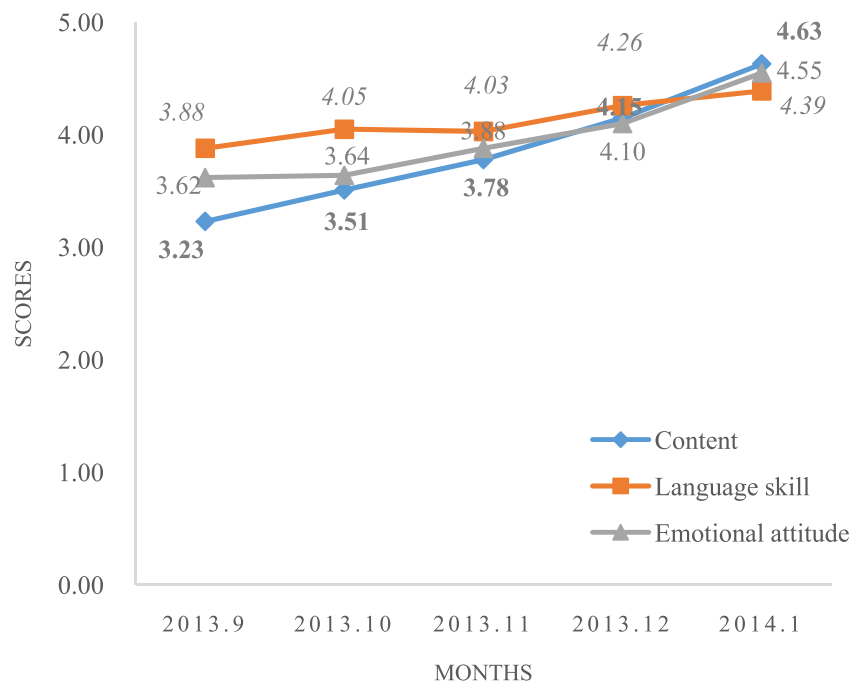

Figure 3: Scores of "describe your own photos"

in all these dimensions. Papa can transmit not only information through words and pictures but also emotion through voice and sounds. Therefore, at the beginning of the semester, the young students achieved lower scores in emotional attitude but improved greatly while using Papa. For content and language skills, practice was the key factor. Through constant practicing, students learned to skip or add some words so as to read more fluently

2. "Describe your own photos"

Average scores month by month with respect to content, language skill and emotional attitude (as shown in Figure 3) were calculated. Steady improvements were observed across the 5 months, especially in aspects of "content" and "emotional attitude." The passion and emotion associated with the photos were quite striking. 


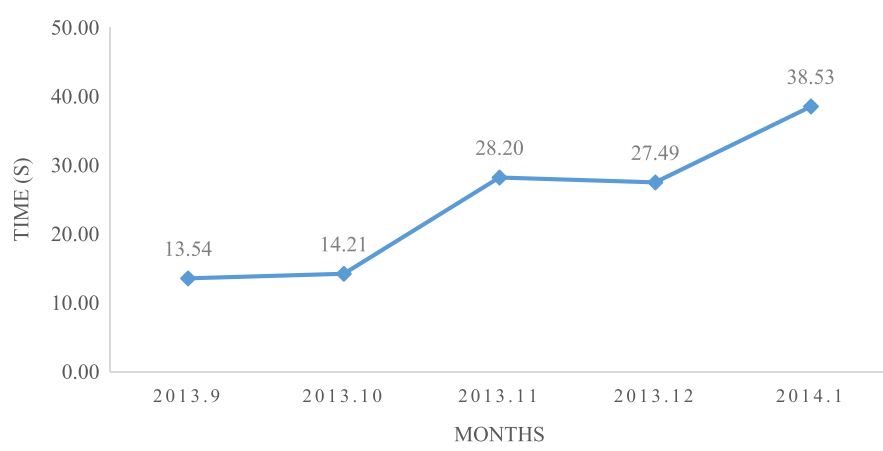

Figure 4: Average time of "describe your own photos"

As a measure of growing confidence in spoken language and sustained engagement, the average duration of "describe your own photos" increased from 13.54 seconds in September 2013 to 28.2 seconds in November 2013 and peaks at 38.53 seconds in January 2014 (Figure 4). We suggest that students' speaking and talking ability are well supported in this procedure.

\section{General discussion}

The ICT-rich learning environment of the 1:1 class is now emerging. Allowing every student to have their own learning device, it has motivated development of e-Textbooks and educational apps. This has greatly increased the possibilities of flexible designs for learning. Recognizing the fact that the potential of pervasive digital access should build upon established cultural contexts, this article has demonstrated the possibilities of innovation with the Chinese "e-Schoolbag" or, more familiarly, a 1:1 class wherein a teacher-led tradition is strongly established.

Both case studies are encouraging examples that illustrate a strategy for addressing a new way of working with new technology. In the first case, we reported a classroom teacher adapting the eTextbook, a technology within the e-Schoolbag: adapting it to work for a classroom with formal textbook traditions that play a central role in organizing classroom discourse. As the case showed, the design opportunities of e-Textbook eased the adoption process for a teacher taking traditional texts as the main tool for shaping their lessons. This new technology therefore recognized a tradition of teaching practice heavily based on the textbook (Li et al, 2009), but allowed the teacher to design lesson plans by transforming, enriching and adjusting the textbook into a "script" to accommodate his contextual needs. In an education system where the textbook has a key role, the design possibility demonstrated in the first case seem to have promise for opening a new trajectory of transformation.

The second case revealed the possibilities for extending classroom traditions of a different kind. It did so by equipping the e-Schoolbag with a social app functioning as a vehicle for building learning community. This new technology was adapted to a classroom with strong traditions of students enjoying performance from their peers. We suggested the value for this kind of practice to deepen learning community experience, especially in a language learning class, which can make greater demands on students' interactions. This case demonstrated that the 1:1 configuration has value in supporting and extending participatory performance in the classroom, and can be an innovative class practice linking the traditions identified by Jin and Cortazzi (1998), with the possibilities that the social technologies provided. These can extend the stage of performance, and the nature of the performance as well as engaging the audience of performance.

We suggest that these are not the only ways in which pedagogy may be flexibly adapted by motivated teachers. For example, authoring suites less governed by the genre of the textbook might 
allow teachers to design resources exploring and celebrating local features of culture, history, or geography in a principled yet engaging manner. Or students might work with local museums and local citizens to produce sound photos that enlivened photographs from the past of their neighborhoods and which could be made accessible through websites.

It is widely understood that educational systems are resilient, that they can be resistant to adopting new practices. This has been theorized in general terms (eg, Lenartowicz, 2014) and in the more specific terms of particular cultural contexts, such as in China (Sang, Valcke, van Braak, Tondeur, \& Zhu, 2011). The challenge of transformation is invariably one of finding convivial points of entry to well-rehearsed forms of cultural practice. So, eg, it is not surprising that the textbook has been seen as one such entry point for many educational technology innovators (Huang, Liang, Su, \& Chen, 2012). However, we may achieve greater traction on acceptance of such novel resources when they are introduced in ways that resonate effectively with existing patterns of expertise or confidence - as felt by both students and teachers. Although innovation in education is never easy, our experience with this project suggests that creative departures from the status quo are possible with sensitive implementations. The cases reported in this article are currently being used as illustrations of possible best practices - supporting teachers who are interested in evolving their own practice in "e-Schoolbag" project schools. It is too early to say that these examples of innovation are going to evolve into part of the routine of daily teaching practice. But they are platforms for ourselves as researchers to explore further opportunities.

\section{Acknowledgements}

This study is supported by Program for New Century Excellent Talents in University (NCET NCET-11-0140).

\section{Statements on open data, ethics and conflict of interest}

This research was conducted under the guideline of Academic ethics and law committee of East China Normal University in full compliance with all ethical and research standard there. No identifying information of participants was kept and none is published. Anyone interested in access to the full data set can contact the corresponding author who will grant access. The authors have no conflicts of interest with regard to any aspects of this research (have no affiliations with or involvement in any organization or entity with any financial interest or non-financial interest in the subject matter or materials discussed in this manuscript). You are welcomed to contact the corresponding author if you have any questions or complaints.

\section{References}

Balanskat, A., Bannister, D., Hertz, B., Sigillò, E., Vuorikari, R., Kampylis, P., et al. (2013). Overview and analysis of 1: 1 learning initiatives in Europe. Publications Office. Retrieved June 8th, 2015 from ftp:// jrc.es/pub/EURdoc/EURdoc/JRC81903.pdf

Bebell, D. \& O'Dwyer, L. M. (2010). Educational outcomes and research from 1: 1 computing settings, Journal of Technology, Learning, and Assessment, 9, 1, 5-15.

Coleman, H. (1996). Shadow puppets and language lessons: interpreting classroom behaviour in its cultural context. In H. Coleman (Ed.), Society and the language classroom (pp. 64-85). Cambridge: Cambridge University Press.

Collins, A. C. \& Halverson, R. (2009). Rethinking Education in the Age of Technology: The Digital Revolution and Schooling in America. New York, NY: Teachers College Press.

Cuban, L. \& Cuban, L. (2009). Oversold and underused: Computers in the classroom. Cambridge, MA: Harvard University Press.

Crook, C. K. \& Lewthwaite, S. (2010). Technologies for formal and informal learning. In: K. Littleton, C. Wood, J. K. Staarman (Eds.), International handbook of psychology in education (pp. 435-461). Bradford, UK: Emerald. 
Doll, W. J. \& Torkzadeh, G. (1998). Developing a multidimensional measure of system-use in an organizational context. Information \& Management, 33, 4, 171-185.

Embong, A. M., Noor, A. M., Hashim, H. M., Ali, R. M., \& Shaari, Z. H. (2012). E-Books as Textbooks in the Classroom. Procedia - Social and Behavioral Sciences, 47, 1802-1809.

Frohlich, D. \& Jones, M. (2008). Audiophoto narratives for semi-literate communities. Interactions, 15, 6 , 61-64.

Friesen, N. (2013). The past and likely future of an educational form a textbook case. Educational Researcher, 42, 9, 498-508.

Goodyear, P. \& Retalis, S. (2010). Technology-enhanced learning: Design patterns and pattern languages. Rotterdam: Sense Publishers.

Gu, X., Fu, W., \& Qi, G. (2012).Connecting reading and learning: design the information model of e-textbook. Journal of East China Normal University (Natural Science), 2, 81-90.

Huang, Y.-M., Liang, T.-H., Su, Y.-N., \& Chen, N.-S. (2012). Empowering personalized learning with an interactive e-book learning system for elementary school students. Educational Technology Research and Development, 60, 4, 703-722.

Jin, L. \& Cortazzi, M. (1998). Dimensions of dialogue: large classes in China. International Journal of Educational Research, 29, 739-761.

Jiang, F., Zheng, J. \& He, P. (2013). The survey of degree of satisfaction and requirements towards eschoolbag: a chinese teachers' perspective. Open Education Research, 4, 012.

Lai, I. K. W. \& Lai, D. C. F. (2013). Hybrid Learning and Continuing Education: 6th International Conference, ICHL 2013, Toronto, ON, Canada, August 12-14, 2013. Proceedings. In S. K. S. Cheung, J. Fong, W. Fong, F. L. Wang, \& L. F. Kwok (Eds.), (pp. 334-344). Berlin, Heidelberg: Springer Berlin Heidelberg.

Lenartowicz, M. (2014). The nature of the university. Higher Education, 69, 6, 947-961.

Li, Y. (2008). What teachers need to do and what they learned in the United States and China. In Z. Usiskin \& E. Willmore (Eds.), Mathematics curriculum in pacific rim countries-China, Japan, Korea, and Singapore (pp. 183-195). Charlotte, NC: Information Age Publishing.

Li, Y., Chen, X., \& Kulm, G. (2009). Mathematics teachers' practices and thinking in lesson plan development: a case of teaching fraction division. ZDM, 41, 6, 717-731.

Lindqvist, M. J. P. H. (2015). Gaining and sustaining tel in a 1:1 laptop initiative: possibilities and challenges for teachers and students. Computers in the Schools, 32, 1, 35-62.

Ma, Y., Zhao, D., \& Tuo, Z. (2004). Differences within Communalities: how is Mathematics Taught in Rural and Urban Regions in Mainland China?. In L. Fan (Ed.), How do Chinese Learn Mathematics? Some perspectives from insiders. Singapore: World Scientific Publishing Company, Incorporated.

Norris, C. \& Soloway, E. (2011) Learning and schooling in the age of mobilism. Educational Technology, 51, $6,3-10$.

Nugroho, D. \& Lonsdale, M. (2010). Evaluation of OLPC programs globally: A literature review(Version 4). Canberra: Australian Council for Educational Research.

Paine, L. W. (1990). The teacher as virtuoso: a Chinese model for teaching. Teachers College Record, 92, 1, $49-82$.

Sang, G., Valcke, M., van Braak, J., Tondeur, J. \& Zhu, C. (2011). Predicting ICT integration into classroom teaching in Chinese primary schools: exploring the complex interplay of teacher-related variables. Journal of Computer Assisted Learning, 27, 2, 160-172.

Sun, Z., Tian, X. \& Shen, H. (2013). A research about personalized recommendations in e-textbook. In 2013 Fourth International Conference on Intelligent Systems Design and Engineering Applications (pp. 44-47).

Tan, C. (2014). Education policy borrowing and cultural scripts for teaching in China. Comparative Education, 51, 1-16.

Tierney, S. (2012). Bring your own device to school. Report by Microsoft Corporation.

Yao, Y. \& Shi, Y. (2013). An empirical analysis of test of language expression ability of students in the lower grades of primary schools. Applied Linguistics, 3, 88-98. (In Chinese) 


\section{Appendix : Language competence scale adapted from Yao and Shi (2013)}

\begin{tabular}{|c|c|c|}
\hline Task & Dimensions & Coding explanation of 1-5 \\
\hline \multirow{12}{*}{$\begin{array}{l}\text { Practice reading } \\
\text { the provided } \\
\text { materials }\end{array}$} & \multirow[t]{4}{*}{ Content } & $\begin{array}{l}\text { 1: Read the words totally incorrectly. Plenty of skipped words or } \\
\text { additive words. }\end{array}$ \\
\hline & & $\begin{array}{l}\text { 2: Read the words correctly. Some skipped words or additive words. } \\
\text { 3: Read the words basically correctly except a few skipped words or } \\
\text { additive words. }\end{array}$ \\
\hline & & $\begin{array}{l}\text { 4: Read the words correctly. Almost no skipped words and additive } \\
\text { words. }\end{array}$ \\
\hline & & $\begin{array}{l}\text { 5: Read the words very correctly. Absolutely no skipped words and } \\
\text { additive words. }\end{array}$ \\
\hline & \multirow[t]{3}{*}{$\begin{array}{l}\text { Language } \\
\text { skill }\end{array}$} & $\begin{array}{l}\text { 1: Cannot read the sentences/articles totally fluently. Plenty of stutters } \\
\text { or pauses. }\end{array}$ \\
\hline & & $\begin{array}{l}\text { 2: Cannot read the sentences/articles fluently. Some stutters or pauses. } \\
\text { 3: Read the sentences/articles basically fluently except a few stutters } \\
\text { or pauses. }\end{array}$ \\
\hline & & $\begin{array}{l}\text { 4: Read the sentences/articles fluently. Almost no stutters and pauses. } \\
\text { 5: Read the sentences/articles very fluently. Absolutely no stutters and } \\
\text { pauses. }\end{array}$ \\
\hline & \multirow[t]{5}{*}{$\begin{array}{c}\text { Emotional } \\
\text { attitude }\end{array}$} & $\begin{array}{l}\text { 1: Express the emotion of the sentences/articles totally wrong. Or no } \\
\text { emotionally expression. }\end{array}$ \\
\hline & & $\begin{array}{l}\text { 2: Express the emotion of the sentences/articles incorrectly. Or a little } \\
\text { bit emotionally expression. }\end{array}$ \\
\hline & & $\begin{array}{l}\text { 3: Express the emotion of the sentences/articles basically correct. } \\
\text { Emotionally expression is accepted. }\end{array}$ \\
\hline & & $\begin{array}{l}\text { 4: Express the emotion of the sentences/articles correctly. Emotionally } \\
\text { expression is good. }\end{array}$ \\
\hline & & $\begin{array}{l}\text { 5: Express the emotion of the sentences/articles very correctly. } \\
\text { Emotionally expression is perfect. }\end{array}$ \\
\hline \multirow[t]{7}{*}{$\begin{array}{l}\text { Describe your } \\
\text { own photos }\end{array}$} & \multirow[t]{5}{*}{ Content } & $\begin{array}{l}\text { 1: Describe the photos in term of time, place, and protagonist, etc., } \\
\text { totally incorrectly. Logical relation of the sentences is totally wrong. } \\
\text { No proper vocabularies. Description is extremely short. }\end{array}$ \\
\hline & & $\begin{array}{l}\text { 2: Describe the photos in term of time, place, and protagonist, etc., } \\
\text { incorrectly. Logical relation of the sentences is ambiguous. Hardly } \\
\text { any proper vocabularies. Description is pretty short. }\end{array}$ \\
\hline & & $\begin{array}{l}\text { 3: Describe the photos in term of time, place, and protagonist, etc., } \\
\text { basically correctly. Logical relation of the sentences can be } \\
\text { understood. A few proper vocabularies. Description is not very long. }\end{array}$ \\
\hline & & $\begin{array}{l}\text { 4: Describe the photos in term of time, place, and protagonist, etc., } \\
\text { correctly. Logical relation of the sentences is good. Some proper } \\
\text { vocabularies. Description is long. }\end{array}$ \\
\hline & & $\begin{array}{l}\text { 5: Describe the photos in term of time, place, and protagonist, etc., } \\
\text { very correctly. Logical relation of the sentences is perfect. Rich in } \\
\text { proper vocabularies. Description is very long. }\end{array}$ \\
\hline & \multirow[t]{2}{*}{$\begin{array}{l}\text { Language } \\
\text { skill }\end{array}$} & $\begin{array}{l}\text { 1: Speck extremely not fluently with incoherent sentences. Plenty of } \\
\text { stutters or pauses. }\end{array}$ \\
\hline & & $\begin{array}{l}\text { 2: Speck pretty not fluently with incoherent sentences. Some stutters } \\
\text { or pauses. }\end{array}$ \\
\hline
\end{tabular}

